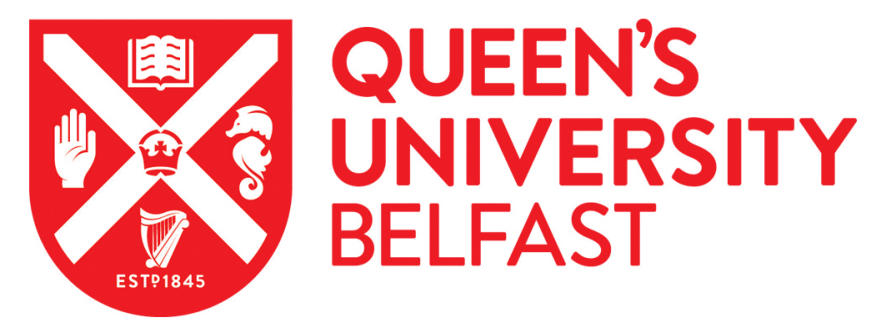

\title{
GLP-1 and related peptides cause concentration-dependent relaxation of rat aorta through a pathway involving KATP and CAMP
}

\author{
Green, B. D., Hand, K. V., Dougan, J. E., McDonnell, B. M., Cassidy, R. S., \& Grieve, D. J. (2008). GLP-1 and \\ related peptides cause concentration-dependent relaxation of rat aorta through a pathway involving $\mathrm{K}$ and \\ cAMP. Archives of Biochemistry and Biophysics, 478(2), 136-142. https://doi.org/10.1016/j.abb.2008.08.801
}

Published in:

Archives of Biochemistry and Biophysics

Document Version:

Publisher's PDF, also known as Version of record

Queen's University Belfast - Research Portal:

Link to publication record in Queen's University Belfast Research Portal

\footnotetext{
General rights

Copyright for the publications made accessible via the Queen's University Belfast Research Portal is retained by the author(s) and / or other copyright owners and it is a condition of accessing these publications that users recognise and abide by the legal requirements associated with these rights.
}

Take down policy

The Research Portal is Queen's institutional repository that provides access to Queen's research output. Every effort has been made to ensure that content in the Research Portal does not infringe any person's rights, or applicable UK laws. If you discover content in the Research Portal that you believe breaches copyright or violates any law, please contact openaccess@qub.ac.uk. 


\title{
GLP-1 and related peptides cause concentration-dependent relaxation of rat aorta through a pathway involving $\mathrm{K}_{\mathrm{ATP}}$ and $\mathrm{CAMP}$
}

\author{
Brian D. Green ${ }^{\mathrm{a}, *}$, Katharine V. Hand ${ }^{\mathrm{a}}$, Janette E. Dougan ${ }^{\mathrm{b}}$, Bronagh M. McDonnell ${ }^{\mathrm{b}}$, \\ Roslyn S. Cassidy ${ }^{\mathrm{b}}$, David J. Grieve ${ }^{\mathrm{b}}$ \\ ${ }^{a}$ Human Nutrition \& Health Group, School of Biological Sciences, Queens University Belfast, David Keir Building, Stranmillis Road, Belfast BT9 5AG, UK \\ ${ }^{\mathrm{b}}$ Cardiovascular Biomedical Research Centre, School of Medicine, Dentistry and Biomedical Sciences, Queens University Belfast, Medical Biology Centre, Lisburn Road, \\ Belfast BT9 7BL, UK
}

\section{A R T I C L E I N F O}

\section{Article history:}

Received 3 April 2008

and in revised form 1 August 2008

Available online 7 August 2008

\section{Keywords:}

Glucagon-like peptide-1 (GLP-1)

Exendin

Incretin

Hormone

Non-peptide agonist

Vasorelaxation

Aorta

\begin{abstract}
A B S T R A C T
Increasing evidence from both clinical and experimental studies indicates that the insulin-releasing hormone, glucagon-like peptide-1 (GLP-1) may exert additional protective/reparative effects on the cardiovascular system. The aim of this study was to examine vasorelaxant effects of GLP-1(7-36)amide, three structurally-related peptides and a non-peptide GLP-1 agonist in rat aorta. Interestingly, all GLP-1 compounds, including the established GLP-1 receptor antagonist, exendin (9-39) caused concentrationdependent relaxation. Mechanistic studies employing hyperpolarising concentrations of potassium or glybenclamide revealed that these relaxant effects are mediated via specific activation of ATP-sensitive potassium channels. Further experiments using a specific membrane-permeable cyclic AMP (cAMP) antagonist, and demonstration of increased cAMP production in response to GLP-1 illustrated the critical importance of this pathway. These data significantly extend previous observations suggesting that GLP-1 may modulate vascular function, and indicate that this effect may be mediated by the GLP-1 receptor. However, further studies are required in order to establish whether GLP-1 related agents may confer additional cardiovascular benefits to diabetic patients.
\end{abstract}

(C) 2008 Elsevier Inc. All rights reserved.
Glucagon-like peptide-1(7-36)amide (GLP-1) is a gut hormone with potent insulin-releasing and glucose-lowering actions. Recent years have seen the clinical development of a number of GLP-1 analogues and mimetic compounds for the treatment of type 2 diabetes. In 2005, the first anti-diabetic drug to target the GLP-1 receptor, exendin-4 (1-39) (also known as exenatide), received approval by the Food and Drug Administration. Numerous similar compounds, which hold vast therapeutic potential for the improved management of type 2 diabetes, are currently undergoing preclinical and clinical trials $[1,2]$.

Recent decades have witnessed an intensive examination of GLP1 's numerous anti-diabetic and metabolic effects [2]. However, emerging evidence now indicates that this peptide hormone may have a number of additional effects on the cardiovascular system. Recent studies report wide-ranging cardiovascular actions of GLP1 such as modulation of heart rate, blood pressure and cardiac structure and function [3-8]. Furthermore, GLP-1 has been shown to improve cardiovascular function in experimental heart failure $[9,10]$ and in both diabetic and non-diabetic heart failure patients $[11,12]$. Chronic GLP-1 treatment has also been found to improve cardiovascular risk factors, such as HDL cholesterol, triglycerides

\footnotetext{
* Corresponding author. Fax: +44 2890976513.

E-mail address: b.green@qub.ac.uk (B.D. Green).
}

and diastolic blood pressure, in patients with type 2 diabetes [13]. Patients with diabetes are characterised by an increased incidence of cardiovascular disease reported to be up to five times that of the normal non-diabetic population [14]. Given the current epidemic escalation in type 2 diabetes and the associated cardiovascular comorbidities, it seems pertinent to further investigate potential cardiovascular actions of anti-diabetic drugs, such as GLP-1 which may prove to be beneficial in the treatment of such complications.

Previous studies investigating the ex vivo vascular actions of GLP1 in rat blood vessels have suggested that it causes direct relaxation via an endothelium-independent mechanism $[15,16]$. The aim of the present study was to significantly extend these preliminary findings to a detailed investigation of the mechanisms by which native GLP-1(7-36)amide, three structurally-related peptides (GLP-1(936)amide, exendin-4 (1-39) and exendin (9-39)) and a small molecule GLP-1 receptor agonist, may modulate vascular function.

\section{Experimental}

\section{Animals}

Male Sprague-Dawley rats (8-12 weeks) were used throughout this study. They were housed under constant climatic conditions with free access to food and water. All experiments were 
performed in accordance with the Guidance on the Operation of the Animals (Scientific Procedures) Act, 1986 (UK).

\section{Isolated vessel studies}

Rats were killed with a sodium pentobarbitone overdose (200 $\mathrm{mg} \mathrm{kg}^{-1}$ body weight i.p.) and the thoracic aorta excised, cleared of surrounding connective tissue, and cut into $3 \mathrm{~mm}$ rings, taking care to leave the endothelium intact. Rings were suspended between a force transducer and fixed support in organ bath chambers containing $1.5 \mathrm{ml}$ modified Krebs-Henseleit buffer (KHB, composition in mM: $118.5 \mathrm{NaCl}, 3.8 \mathrm{KCl}, 1.18 \mathrm{KH}_{2} \mathrm{PO}_{4}, 25 \mathrm{NaHCO}_{3}$, $1.19 \mathrm{MgSO}_{4}, 10$ glucose and $1.25 \mathrm{CaCl}_{2}$ ), bubbled with $95 \% \mathrm{O}_{2} / 5 \%$ $\mathrm{CO}_{2}$ at $37^{\circ} \mathrm{C}$. Vessels were held at a resting tension of $1 \mathrm{~g}$ (preliminary experiments found this to be optimal), and allowed to equilibrate for $45 \mathrm{~min}$, before the maximum contractile response to $80 \mathrm{mM} \mathrm{KCl}$ was assessed. Following washout and re-equilibration, a cumulative dose response curve to phenylephrine (PE, $1 \mathrm{nM}-10 \mu \mathrm{M})$ was performed. After washout, rings were then pre-constricted with PE to $70 \%$ of their maximal PE-induced contraction before the following experimental protocols were performed.

In order to study the direct effects of GLP-1 compounds on vascular function, cumulative relaxation responses were performed to the peptides GLP-1(7-36)amide, GLP-1(9-36)amide, exendin-4 (139) and exendin (9-39) and the non-peptide small molecule GLP1 receptor agonist 6,7-dichloro-2-methylsulfonyl-3- $N$-tert-butylaminoquinoxaline (DMB) $(0.1 \mathrm{pM}-0.1 \mu \mathrm{M})$. Possible mechanisms of action of GLP-1 were further investigated by performing cumulative relaxation responses to GLP-1(7-36)amide in endotheliumdenuded vessels and in the presence or absence of the following specific inhibitors of candidate pathways $(n=8-13)$ : (1) $N_{\omega}$-nitro-L-arginine methyl ester hydrochloride (L-NAME, $0.3 \mathrm{mM}$ ), non-selective nitric oxide (NO) synthase inhibitor; (2) indomethacin $(10 \mu \mathrm{M})$, cyclooxygenase inhibitor; (3) catalase (1250 $\left.\mathrm{U} \mathrm{ml}^{-1}\right)$, hydrogen peroxide scavenger; (4) hyperpolarising potassium (30 mM KCl); (5) glybenclamide $(10 \mu \mathrm{M})$, ATP-sensitive potassium channel blocker; (6) Rp-8-Br-cAMPS $(10 \mu \mathrm{M})$, cell-permeable cyclic AMP (cAMP ${ }^{1}$ ) antagonist. Cumulative relaxation response curves were also performed to the cAMP activator, forskolin $(0.1 \mathrm{mM})$ in the presence and absence of Rp-8-Br-cAMPS, in order to demonstrate the specificity of the inhibitor for cAMP.

\section{Determination of cAMP production}

Rats ( $n=8-12$ ) were killed and the thoracic aorta removed, cleaned and cut into two sections. Each vessel segment was equilibrated for $30 \mathrm{~min}$ in $\mathrm{KHB}$ at $37{ }^{\circ} \mathrm{C}$ and bubbled with $95 \% \mathrm{O}_{2} / 5 \%$ $\mathrm{CO}_{2}$, before incubation with the non-specific phosphodiesterase inhibitor, 3-isobutyl-1-methylxanthine(IBMX, 0.1 mM) for a further $10 \mathrm{~min}$. One vessel section was then incubated with GLP-1(736)amide or exendin (9-39) $(0.1 \mu \mathrm{M})$ for $15 \mathrm{~min}$ and the other with an equivalent volume of vehicle to act as a control. Vessels were then blotted dry and frozen in liquid nitrogen for further analysis.

For determination of cAMP production, frozen aortae were weighed and homogenised (1500 rpm) using a reusable pellet pestle (Kimble-Kontes, Vineland, New Jersey, USA) fixed into an overhead stirrer (SS10, Stuart Scientific, Surrey, UK). Homogenates were suspended in trichloroacetic acid (5\% (w/v); $100 \mu \mathrm{l} / 100 \mathrm{mg}$ of tissue), centrifuged (1500g, $10 \mathrm{~min}$ ) and the supernatant was re-

\footnotetext{
${ }^{1}$ Abbreviations used: cAMP, cyclic AMP; DMB, 6,7-Dichloro-2-methylsulfonyl-3- $N$ tert-butylaminoquinoxaline; DPP IV, dipeptidyl peptidase IV; GLP-1, glucagon-like peptide-1; IBMX, 3-isobutyl-1-methylxanthine; KHB, Krebs-Henseleit buffer; LNAME, $N_{\omega}$-nitro- L-arginine methyl ester hydrochloride; NO, nitric oxide; PE, phenylephrine.
}

moved. Trichloroacetic acid was extracted from samples using water-saturated diethyl ether before total cAMP production was measured using an enzyme immunoassay kit (Cayman Europe, Tallinn, Estonia).

\section{Real-time RT-PCR}

Expression of GLP-1 receptor mRNA was analysed in rat aorta, skeletal muscle (gastrocenimus) and heart by real-time RT-PCR with fluorescent SYBR Green technology on a Prism 7300 HT system (Applied Biosystems, Warrington, UK), using $\beta$-actin mRNA for normalisation. Primers (5'-3'): $\beta$-actin: forward CGTGAAAAGATGACCCAGATCA, reverse TGGTACGACCAGAGGCATACAG; GLP1 receptor: forward CATCCACCTGAACCTGTTTGC, reverse GGGCAGCGTCTTTGATGAA. The comparative $\mathrm{Ct}$ method was used for relative quantification with validation experiments demonstrating approximately equal efficiencies of primers. All samples were run in triplicate and data expressed in arbitrary units.

\section{Reagents}

GLP-1 and exendin peptides (>95\% purity) were custom made by EZbiolabs (Indiana, USA). L-phenylephrine hydrochloride (PE), $N_{\omega}$-nitro-L-arginine methyl ester hydrochloride (L-NAME), indomethacin, catalase, glybenclamide, forskolin and 3-isobutyl-1methylxanthine (IBMX) were purchased from Sigma-Aldrich (Poole, UK). Rp-8-Br-cAMPS and 6,7-dichloro-2-methylsulfonyl-3$\mathrm{N}$-tert-butylaminoquinoxaline (DMB) were purchased from Merck Chemicals Ltd (Nottingham, UK). All drugs, with the exception of indomethacin, were initially dissolved in deionised water (at $10 \mathrm{mM}$ ) and diluted in KHB. Indomethacin was initially dissolved in dimethyl sulphoxide (at $0.1 \mathrm{M}$ ) and diluted in KHB. All solutions were freshly prepared on the day of the experiment. Concentrations are expressed as the final concentration of each drug in the organ bath.

\section{Statistical analysis}

Data are expressed as mean \pm standard error of the mean (SEM). For organ bath studies data was expressed as decrease in tension calculated as a percentage of the initial PE-induced tension, and was plotted against log agonist concentration. Production of cAMP and GLP-1 receptor mRNA were expressed as arbitrary units. Data were analysed by a two-way repeated measures ANOVA, one-way ANOVA with Tukey's post-hoc test or unpaired Student's $t$ test (two-tailed), as appropriate. $P<0.05$ was considered to be significant.

\section{Results}

Effects of GLP-1 and structurally-related peptides on vascular relaxation in isolated rat aorta

Fig. 1 shows cumulative relaxation response curves to (A) GLP1(7-36)amide and GLP-1(9-36)amide, (B) exendin-4 (1-39) and exendin (9-39) and (C) GLP-1(7-36)amide and DMB. All five compounds elicited significant and concentration-dependent vasorelaxation actions in rat aorta. Maximal relaxations to endogenous GLP-1(7-36)amide and GLP-1(9-36)amide (52.1 \pm 7.0 and $45.8 \pm 8.2 \%)$ appeared to be greater than those to synthetic exendin-4 (1-39) and exendin (9-39) (32.5 \pm 7.8 and $33.7 \pm 6.6 \%$ ), although this did not reach statistical significance $(P=0.086$, oneway ANOVA). The non-peptide GLP-1 receptor agonist, DMB induced similar maximal relaxations to GLP-1(7-36)amide (55.1_ \pm 5.7 vs $60.9 \pm 8.9 \%)$. These data are summarised in Fig. $1 \mathrm{D}$. 
A
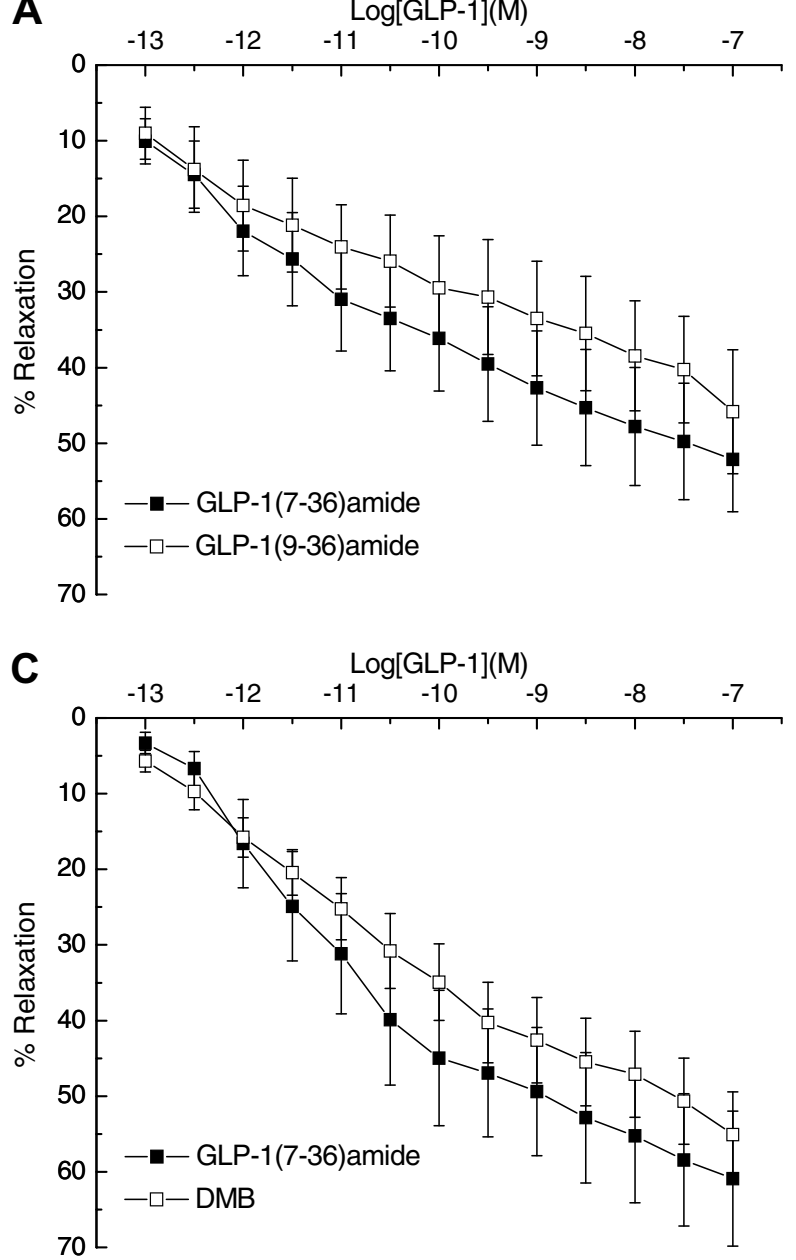

B

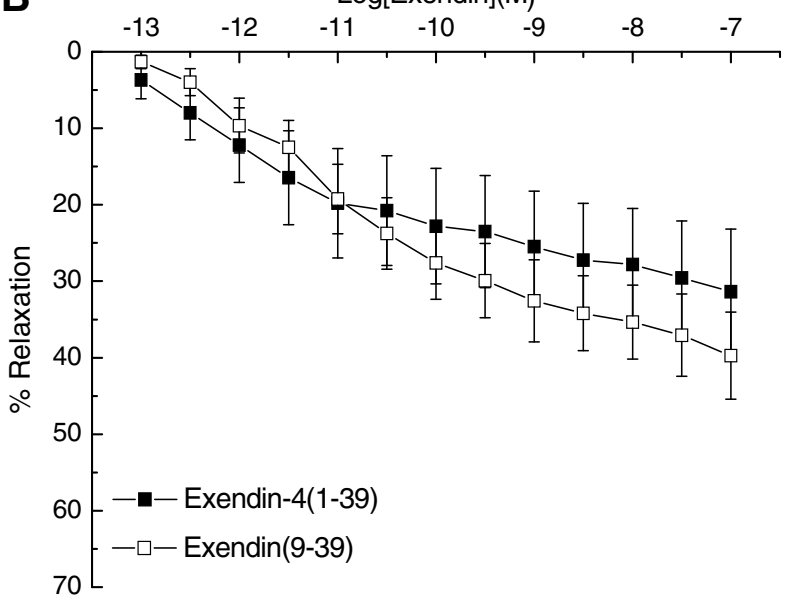

D

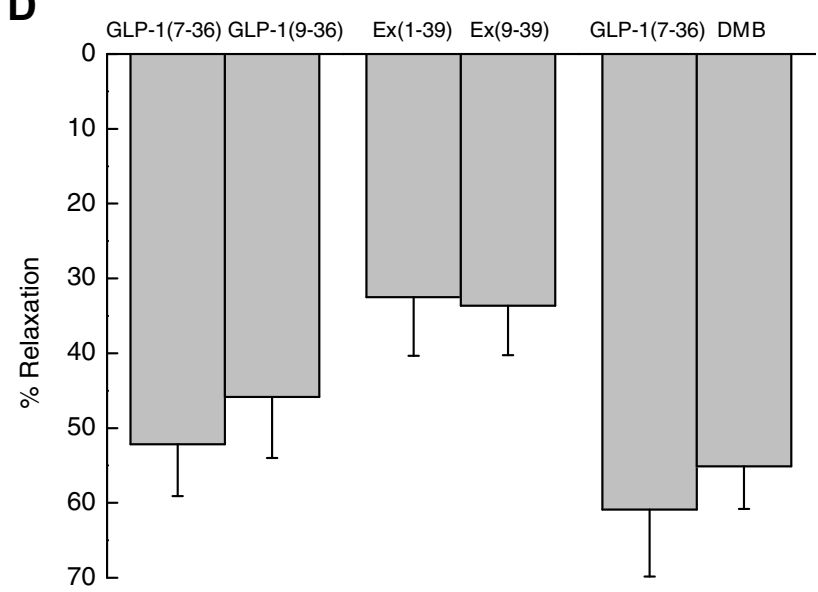

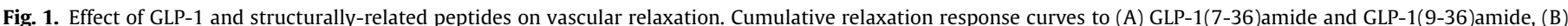

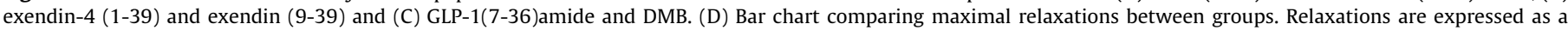

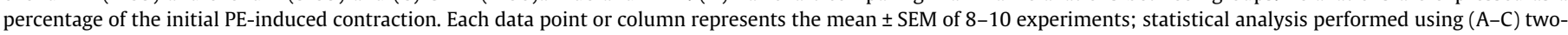
way repeated measures ANOVA and $(D)$ one-way ANOVA $(P=N S)$.

\section{Mechanisms of GLP-1-mediated vascular relaxation}

Based on these data, the predominate physiological isoform, GLP-1(7-36)amide (herein referred to as GLP-1), was selected for a number of further mechanistic studies. Neither endothelial denudation nor incubation with the NO synthase inhibitor, L-NAME, the cyclooxygenase inhibitor, indomethacin or the hydrogen peroxide scavenger, catalase had any significant effect on relaxation to GLP-1 (Fig. 2). In contrast, cumulative relaxation responses to GLP-1 were significantly attenuated by both high extracellular potassium and the ATP-sensitive potassium channel blocker, glybenclamide (Fig. 3A-B; control 55.9 \pm 6.1 , high $\mathrm{KCl} 30.2 \pm 7.2$, glybenclamide $26.6 \pm 7.3 \%$; $P<0.05$ ). Maximal relaxation responses from all of these inhibitor studies are summarised in Fig. 3C.

Further studies demonstrated that pre-incubation of vessels with the specific cAMP antagonist, Rp-8-Br-cAMPS significantly inhibited relaxations induced by both GLP-1 (Fig. 4A; $33.9 \pm 8.3$ vs $66.0 \pm 3.7 \% ; P<0.05)$ and the adenylate cyclase activator, forskolin (Fig. 4B; $\mathrm{EC}_{50}, 13.2 \pm 6.0$ vs $2.1 \pm 0.8 \mu \mathrm{M} ; P<0.05$ ), the latter experiment confirming the specificity of $\mathrm{Rp}-8-\mathrm{Br}$-cAMPS for cAMP. Consistent with these findings, cAMP production was found to be significantly increased in aortic vessels incubated with GLP-1 compared with vehicle controls (Fig. 4C; $1.00 \pm 0.19$ vs $1.90 \pm 0.31$ arbitrary units; $P<0.05)$. Interestingly, exendin (9-39) was also found to significantly stimulate cAMP production compared with controls (Fig. $4 C ; 1.00 \pm 0.29$ vs $1.95 \pm 0.35$ arbitrary units; $P<0.05$ ).

\section{Quantitative expression of the GLP-1 receptor in rat aorta}

Significant expression of GLP-1 receptor mRNA was demonstrated in rat aorta by real-time RT-PCR (Fig. 5). Heart and skeletal muscle were used for positive and negative comparison as tissues in which the GLP-1 receptor is known to be expressed at very high and very low levels, respectively [17].

\section{Discussion}

In this study we demonstrated that GLP-1 causes significant concentration-dependent relaxation of isolated rat aorta through mechanisms leading to stimulation of cAMP and subsequent opening of $K_{\text {ATP }}$ channels. This effect occurs independently of its established insulin-releasing activity and does not appear to be modulated by the primary physiological inactivator of GLP-1, dipeptidyl peptidase IV (DPP IV). The potent vasorelaxant activity of a small molecule non-peptide GLP-1 receptor agonist (DMB) [38] suggests that this effect may at least partly be mediated via the GLP-1 receptor. Taken together, these are important observations which may have significant implications for the therapeutic 
A

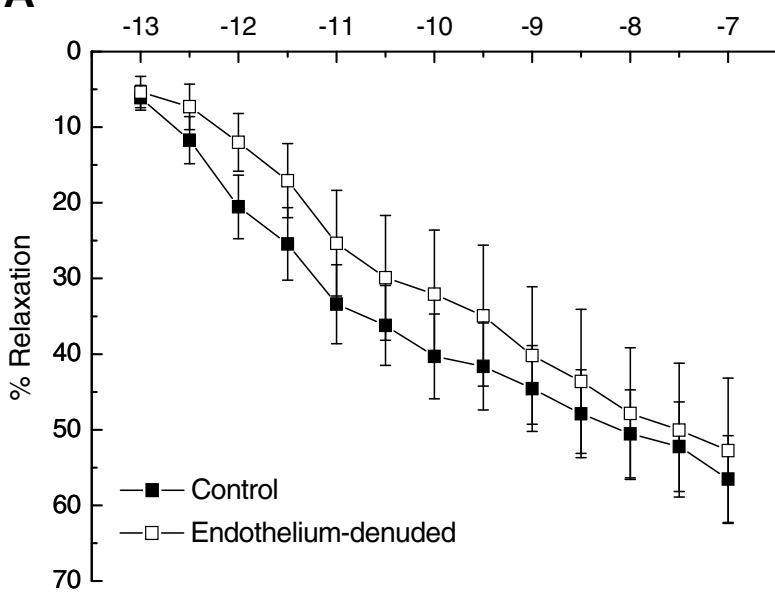

c

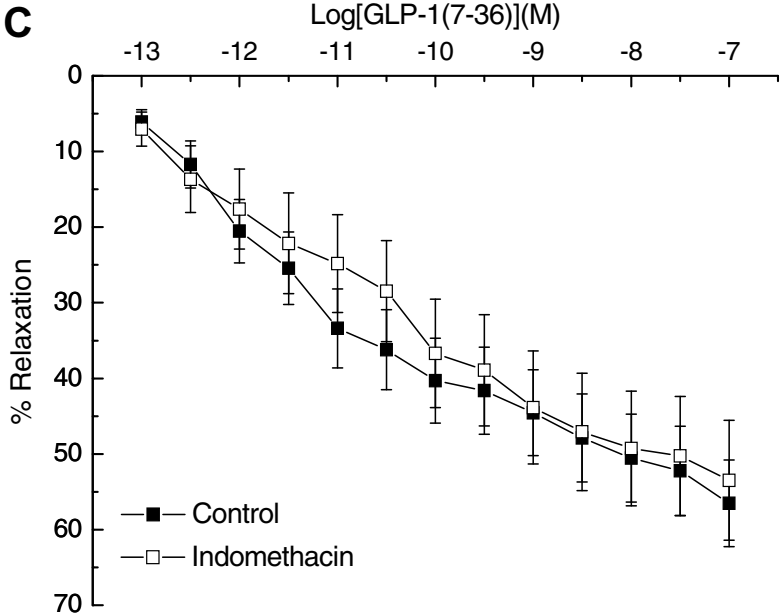

B

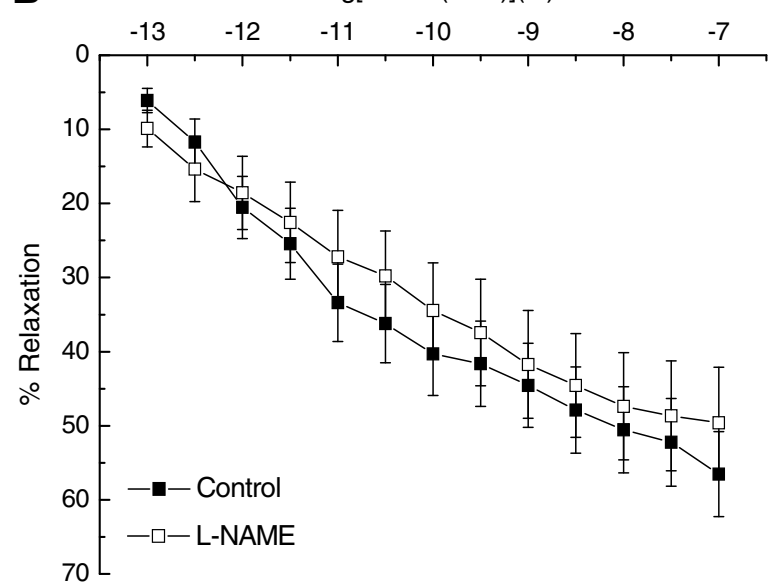

D

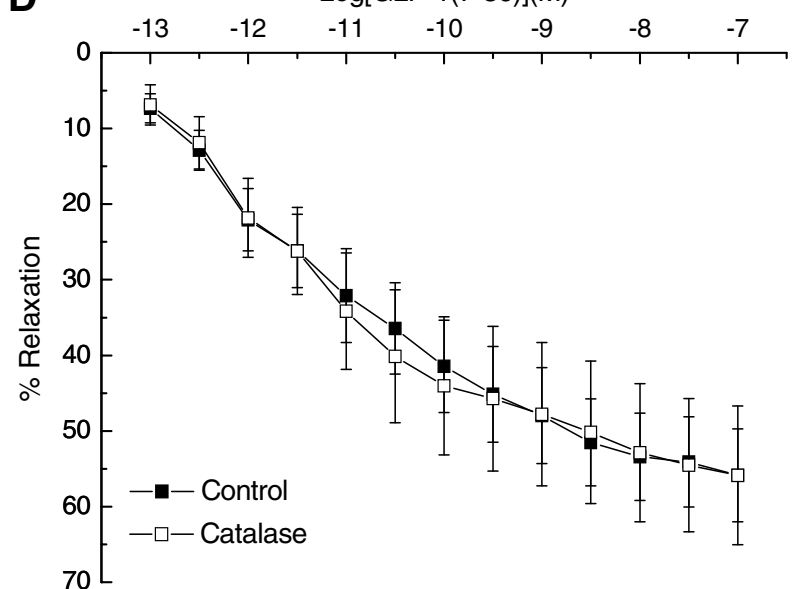

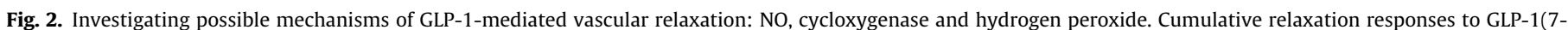

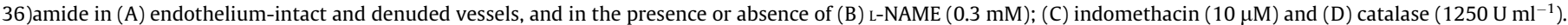

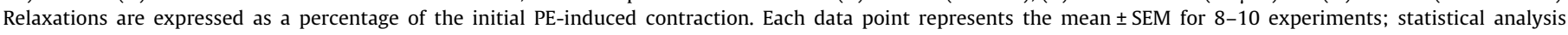
performed using two-way repeated measures ANOVA $(P=\mathrm{NS})$.

use of GLP-1 in the treatment of vascular complications associated with diabetes.

We chose to investigate the effects of GLP-1(7-36)amide and three structurally-related peptides, GLP-1(9-36)amide, exendin-4 (1-39) and exendin (9-39) on vascular relaxation. These peptides are characterised by differing biological activities as outlined in Table 1 . The majority of circulating GLP-1 is found in the form of GLP1(7-36)amide. This insulin-releasing peptide is rapidly degraded in vivo by DPP IV to generate its major plasma metabolite, GLP1(9-36)amide [18]. GLP-1(9-36)amide is largely devoid of insulin-releasing activity, has lower affinity for the GLP-1 receptor and does not attenuate hyperglycaemic excursion [19-24]. Exendin-4 (1-39) is a peptide isolated from the salivary glands of the Gila monster lizard which possesses $53 \%$ sequence homology to GLP-1 and is a potent GLP-1 receptor agonist [21]. Exendin (939 ) is a well characterised antagonist of the GLP-1 receptor which has been demonstrated on numerous occasions to block the biological actions of both GLP-1(7-36)amide and exendin-4 (1-39) $[20,21,23,25-27]$. Indeed, a previous study on the ex vivo vascular actions of GLP-1 reported that exendin (9-39) significantly inhibited GLP-1-induced relaxations in rat femoral artery [16]. However, in the present investigation we clearly demonstrated that this pep-

Table 1

Functional characteristics of GLP-1 peptides employed in these studies

\begin{tabular}{|c|c|c|c|c|}
\hline Functional characteristic & GLP-1(7-36)amide & GLP-1(9-36)amide & Exendin-4 (1-39) & Exendin (9-39) \\
\hline Stimulate insulin secretion? $[1,2,31]$ & Yes & No & Yes & No \\
\hline GLP-1 receptor agonist/antagonist? [21-23,31] & Agonist & Inactive/weak antagonist & Agonist & Antagonist \\
\hline Stimulate production of cAMP in beta cells? $[1,2,21,23,31]$ & Yes & No & Yes & No \\
\hline Relative affinity for GLP-1 receptor compared with GLP-1(7-36)amide $[21,23,31]$ & $\mathrm{N} / \mathrm{A}$ & $\sim 100-150$-fold $\downarrow$ & Similar & 3-6-fold $\downarrow$ \\
\hline Cause vasorelaxation in isolated rat aorta? (present study) & Yes & Yes & Yes & Yes \\
\hline Stimulate cAMP production in isolated rat aorta? (present study) & Yes & ns & ns & Yes \\
\hline Cause vasorelaxation in isolated femoral arteries? [16] & Yes & ns & ns & No \\
\hline
\end{tabular}

N/A, not applicable; ns, not studied; $\downarrow$, decrease. 
A

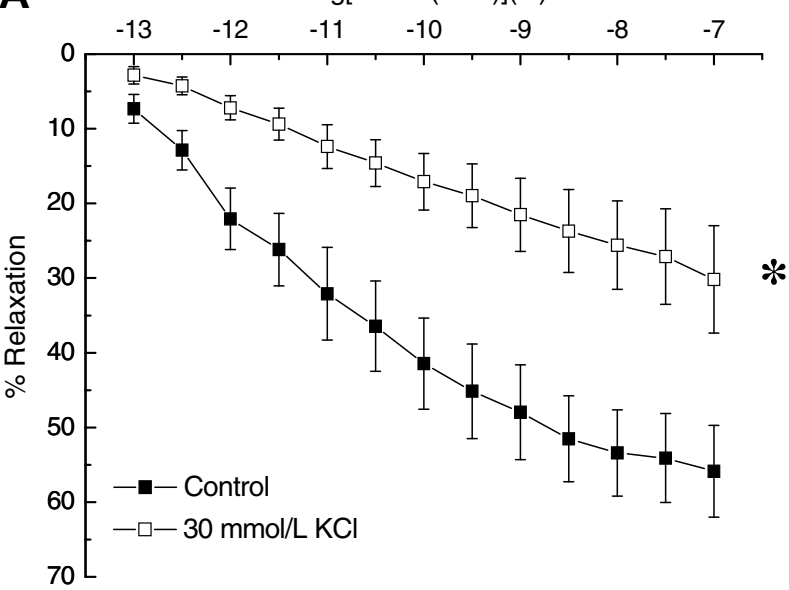

B
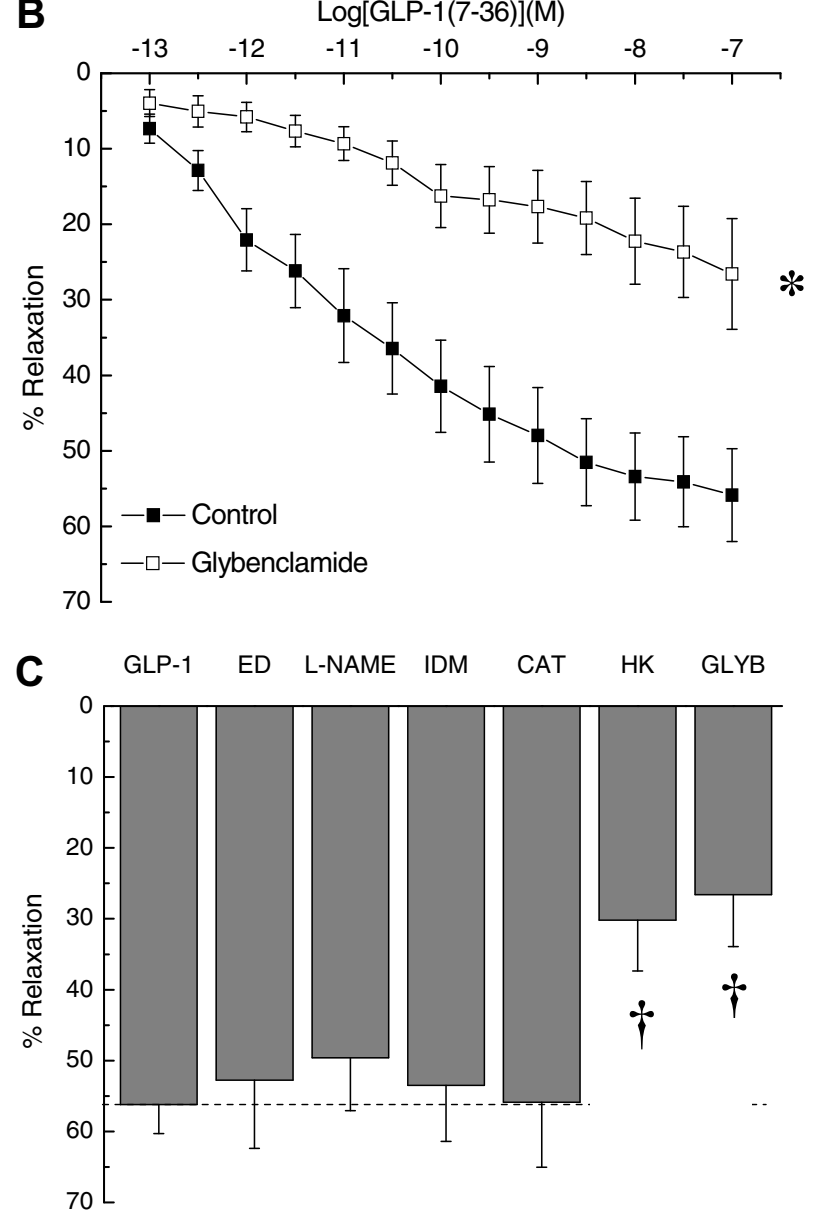

Fig. 3. Investigating the role of extracellular potassium and $\mathrm{K}_{\mathrm{ATP}}$ channels in GLP-1mediated vascular relaxation. Cumulative relaxation responses to GLP-1(7$36)$ amide in the presence or absence of $(A)$ high extracellular potassium $(30 \mathrm{mM})$ and (B) glybenclamide $(10 \mu \mathrm{M})$. (C) Bar chart summarising the effects of endothelial denudation (ED), L-NAME, indomethacin (IDM), catalase (CAT), hyperpolarising potassium (HK) and glybenclamide (GLYB) on maximal relaxation responses to GLP-1(7-36)amide. Results are expressed as a percentage of the initial PE-induced contraction. Each value represents the mean \pm SEM for 8-10 experiments; $P<0.05$ vs control (two-way repeated measures ANOVA), ${ }^{\dagger} P<0.05$ vs GLP-1 (one-way ANOVA with Tukey's post-hoc test).

tide had a potent concentration-dependent relaxant effect of similar magnitude to each of the other GLP-1 peptides tested, suggesting that GLP-1-induced vascular relaxation, at least in the rat aorta, may occur independently of its established metabolic actions.
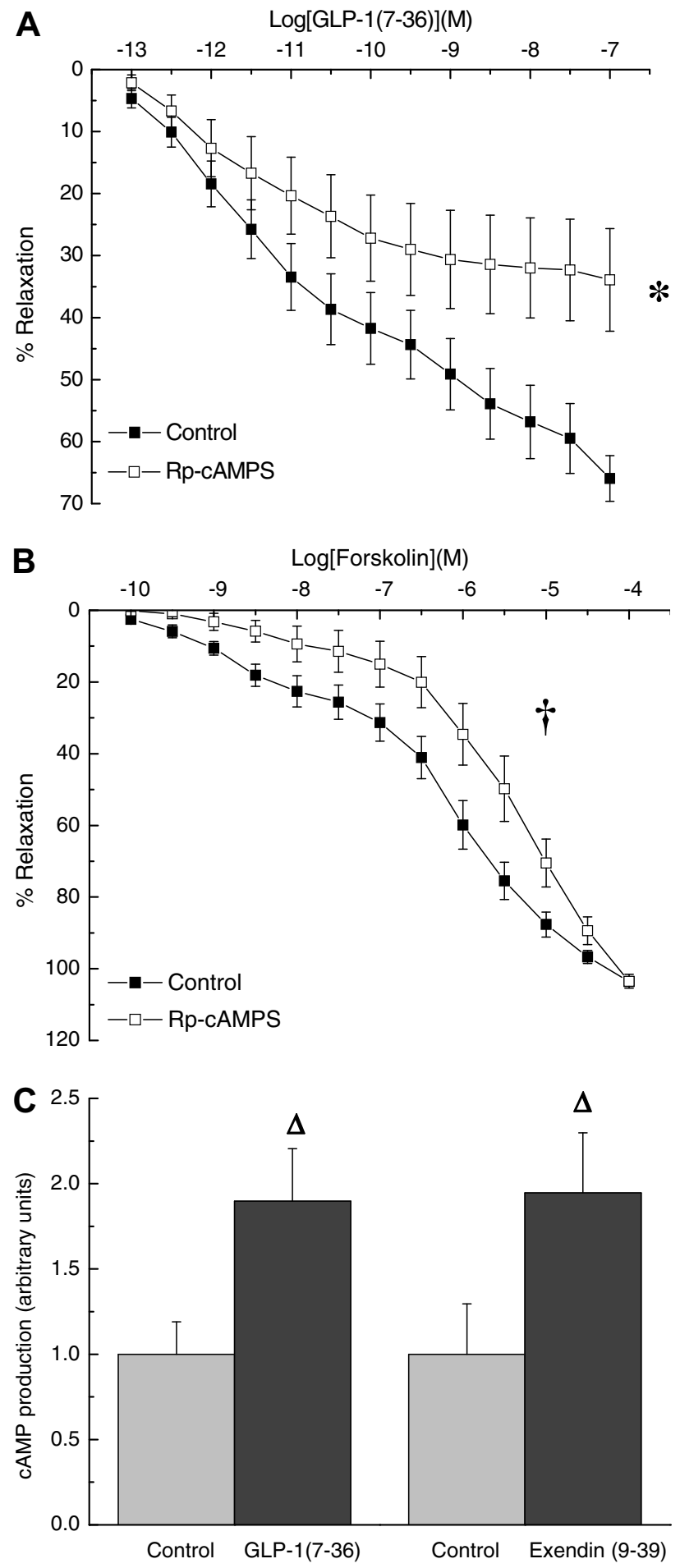

Fig. 4. Involvement of CAMP in GLP-1-induced vascular relaxation. Cumulative relaxation responses to (A) GLP-1(7-36)amide and (B) forskolin in the presence or absence of Rp-8-Br-cAMPS $(10 \mu \mathrm{M})$. (C) cAMP production in vessels incubated with and without GLP-1(7-36)amide or exendin (9-39) $(0.1 \mu \mathrm{M})$. Results for vascular function experiments are expressed as a percentage of the initial PE-induced contraction; results for cAMP assay are expressed as arbitary units. Each value represents the mean \pm SEM for $7-12$ experiments; ${ }^{P} P<0.05$ vs control (two-way repeated measures ANOVA), ${ }^{\dagger} P<0.05$ between $\mathrm{EC}_{50}$ values (two-tailed unpaired Student's $t$ test), $\Delta P<0.05$ vs corresponding control (one-way ANOVA with Tukey's post-hoc test).

Interestingly, recent studies have also reported similar potencies of GLP-1(7-36)amide and GLP-1(9-36)amide. In conscious dogs with pacing-induced heart failure, Nikolaidis et al. found that 


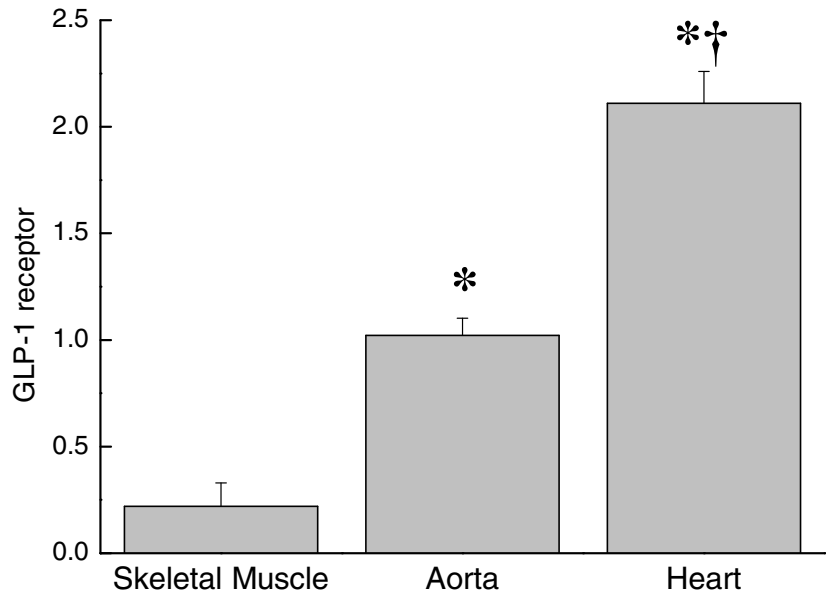

Fig. 5. GLP-1 receptor expression. Bar chart comparing mRNA expression of GLP-1 receptor in rat aorta, heart and skeletal muscle. Each value represents the mean \pm SEM for six samples; ${ }^{*} P<0.05$ vs skeletal muscle, ${ }^{\dagger} P<0.05$ vs aorta (oneway ANOVA with Tukey's post-hoc test).

both GLP-1(7-36)amide and GLP-1(9-36)amide significantly improved left ventricular function [9]. Similarly, Sonne et al. demonstrated that both exendin-4 (1-39) and GLP-1(9-36)amide were able to augment left ventricular performance in a rat heart ischaemia-reperfusion model [28]. These studies support our suggestion that, in contrast to insulin secretion, the vascular actions of GLP-1 may not be influenced by endogenous DPP IV degradation, which is important as circulating levels of GLP-1(9-36)amide are typically higher than those of GLP-1(7-36)amide. Therefore GLP-1(936)amide, a peptide often referred to as 'inactive', may have more physiological significance than has previously been acknowledged.

In the present study, the predominant physiological isoform, GLP-1(7-36)amide was selected to further probe several potential mechanisms underlying this relaxant effect. A common mediator of vascular relaxation is NO, released from endothelial cells via conversion of L-arginine by NO synthase. However, in this study neither endothelial denudation nor inhibition of NO by L-NAME affected GLP-1-induced relaxation, findings which are supported by an earlier study in rat femoral artery [16]. Cyclooxygenase converts arachidonic acid to its prostanoid metabolites, many of which have vasodilatory properties. However, the cyclooxygenase inhibitor, indomethacin had no significant effect on responses to GLP-1, suggesting that its vasorelaxant action is not mediated through this pathway. Under certain conditions increased oxidative stress can lead to production of vasoactive hydrogen peroxide via the catalytic conversion of superoxide by superoxide dismutase. However, pre-incubation with the hydrogen peroxide scavenger, catalase had no significant effect on relaxations to GLP-1 suggesting that generation of hydrogen peroxide is not involved in this setting.

As none of the above pathways were found to be involved in the vasorelaxant actions of GLP-1, we decided to interrogate potential effects of GLP-1 on membrane hyperpolarisation. Indeed, increasing the extracellular potassium concentration to $30 \mathrm{mM}$, which is known to completely block membrane hyperpolarisation, significantly attenuated GLP-1-induced relaxations, suggesting the involvement of a hyperpolarisation-dependent pathway. As GLP-1 has been shown to stimulate ATP-sensitive potassium channels in the pancreas $[29,30]$, which are also known to mediate vascular relaxation, it seemed likely that GLP-1 may also activate these channels in our preparation. Indeed, pre-incubation with the ATP-sensitive potassium channel blocker, glybenclamide significantly reduced the vasorelaxant response to GLP-
1 indicating the specific involvement of ATP-sensitive potassium channels.

GLP-1 is known to be a potent stimulator of cAMP production and activation of this pathway frequently leads to vasorelaxation [31]. In the present study, we demonstrated that Rp-cAMPS, a specific membrane-permeable antagonist of cAMP, which prevents the activation of protein kinase A, significantly attenuated relaxations to GLP-1. Furthermore, incubation with GLP-1 and exendin (9-39), which also caused vasorelaxation, resulted in a significant elevation in vascular cAMP production. The specificity of RpcAMPS for cAMP was confirmed by isolated vessel studies in which it was found to significantly decrease vascular sensitivity to the adenylate cyclase activator, forskolin, consistent with previous reports [32-33]. Taken together these studies provide convincing evidence for the involvement of a cAMP-dependent pathway in GLP-1-induced vascular relaxation.

The GLP-1 receptor is a G-protein-coupled receptor widely expressed in tissues including pancreas, kidney, stomach, and brain [34], and to a much lesser extent in muscle and adipose tissues [17]. Although the GLP-1 receptor has been identified in the hearts of many species including humans, expression in other parts of the cardiovascular system has not yet been characterised $[11,31,35,36]$. In the present study, quantitative molecular analyses indicated marked mRNA expression of the GLP-1 receptor in rat aorta, which was significantly higher than that found in skeletal muscle but less abundant than heart tissue. Our studies using the non-peptide GLP-1 receptor agonist, $\mathrm{DMB}$, provide evidence supporting a role for the GLP-1 receptor in the observed relaxation response. Indeed, in well characterised tissues such as pancreas, the GLP-1 receptor is known to regularly couple to and activate adenylate cyclase leading to cAMP production and subsequent activation of protein kinase $A$ [31]. However, since GLP-1(9-36)amide and exendin (9-39) (previously referred to as antagonists) also cause vascular relaxation and increased cAMP production, it would appear that the GLP-1 receptor may be differentially activated in the vasculature compared to other tissues. Further detailed investigations are required in order to establish the precise role of the GLP-1 receptor in GLP-1 mediated vascular relaxation.

Diabetic patients are characterised by an increased risk of developing debilitating microvascular complications such as retinopathy, nephropathy and neuropathy [37]. Previous studies indicate that GLP-1 may actually increase arterial blood pressure secondary to sympathetic activation and tachycardia, thus masking any potential hypotensive effect $[3,4]$. However, it is possible that GLP-1 may still confer cardiovascular benefits in mediating local vasodilatation of peripheral tissues, which combined with increased arterial blood pressure could serve to increase delivery of oxygenated blood to compromised tissues. The potential for GLP-1 to improve tissue perfusion in diabetic patients and reduce the incidence/severity of microvascular complications is an exciting development and one that warrants further investigation. Interestingly, our data suggest that this may also apply to peptides which have previously been reported as 'inactive', such as GLP-1(9-36)amide.

In conclusion, these studies demonstrate that GLP-1 and a number of structurally-related peptides have significant vasorelaxant properties. The relaxant action of GLP-1 appears to be mediated, at least in part via stimulation of cAMP and opening of ATP-sensitive potassium channels. The unexpected relaxant actions of metabolically-inactive forms of GLP-1 raise important questions concerning the activation and coupling of vascular GLP-1 receptor. Further studies are required in order to establish whether the clinical use of GLP-1 as an anti-diabetic drug therapy may also provide additional cardiovascular benefits to these patients. 


\section{Acknowledgments}

The authors are currently supported by project funding from Diabetes UK. KVH and BMD were supported by summer studentships from the Physiological Society and the School of Medicine, Dentistry and Biomedical Sciences, Queen's University Belfast. The authors do not consider that they have any conflict of interest that would prejudice the impartiality of this scientific work.

\section{References}

[1] B.D. Green, P.R. Flatt, Best Pract. Res. Clin. Endocrinol. Metab. 21 (2007) 497516.

[2] L.L. Baggio, D.J. Drucker, Gastroenterology 132 (2007) 2131-2157.

[3] J.M. Barragán, R.E. Rodríguez, E. Blázquez, Am. J. Physiol. 266 (1994) E459E466.

[4] H. Yamamoto, C.E. Lee, J.N. Marcus, T.D. Williams, J.M. Overton, M.E. Lopez, A.N. Hollenberg, L. Baggio, C.B. Saper, D.J. Drucker, J.K. Elmquist, J. Clin. Invest. 110 (2002) 43-52.

[5] M. Yu, C. Moreno, K.M. Hoagland, A. Dahly, K. Ditter, M. Mistry, R.J. Roman, J. Hypertens. 21 (2003) 1125-1135.

[6] R. Gros, X. You, L.L. Baggio, M.G. Kabir, A.M. Sadi, I.N. Mungrue, T.G. Parker, Q. Huang, D.J. Drucker, M. Husain, Endocrinology 114 (2003) 2242-2252.

[7] M.G. Vila Petroff, J.M. Egan, X. Wang, S.J. Sollott, Circ. Res. 89 (2001) 445-452.

[8] C. Saraceni, T.L. Broderick, Drugs R.D. 8 (2007) 145-153.

[9] L.A. Nikolaidis, D. Elahi, T. Hentosz, A. Doverspike, R. Huerbin, L. Zourelias, C. Stolarski, Y.T. Shen, R.P. Shannon, Circulation 110 (2004) 955-961.

[10] L.A. Nikolaidis, D. Elahi, Y.T. Shen, R.P. Shannon, Am. J. Physiol. Heart Circ. Physiol. 289 (2005) H2401-H2408.

[11] T. Nystrom, M.K. Gutniak, Q. Zhang, F. Zhang, J.J. Holst, B. Ahren, A. Sjoholm, Am. J. Physiol. Endocrinol. Metab. 287 (2004) E1209-E1215.

[12] G.G. Sokos, L.A. Nikolaidis, S. Mankad, D. Elahi, R.P. Shannon, J. Card. Fail. 12 (2006) 694-699.

[13] L. Blonde, J. Rosenstock, C. Triplitt, J. Manag, Care Pharm. 12 (2006) S2-S12.

[14] W.B. Kannel, D.L. McGee, JAMA 241 (1979) 2035-2038.

[15] H.A. Golpon, A. Puechner, T. Welte, P.V. Wichert, C.O. Feddersen, Regul. Pept. 102 (2001) 81-86
[16] T. Nyström, A.T. Gonon, A. Sjöholm, J. Pernow, Regul. Pept. 125 (2005) 173177.

[17] H. Sandhu, S.R. Wiesenthal, P.E. MacDonald, R.H. McCall, V. Tchipashvili, S Rashid, M. Satkunarajah, D.M. Irwin, Z.Q. Shi, P.L. Brubaker, M.B. Wheeler, M Vranic, S. Efendic, A. Giacca, Diabetes 48 (1999) 1045-1053.

[18] R. Mentlein, B. Gallwitz, W.E. Schmidt, Eur. J. Biochem. 214 (1993) 829-835.

[19] C.F. Deacon, A.H. Johnsen, J.J. Holst, J. Clin. Endocrinol. Metab. 80 (1995) $952-$ 957

[20] C. Montrose-Rafizadeh, H. Yang, B.D. Rodgers, A. Beday, L.A. Pritchette, J. Eng, J. Biol. Chem. 272 (1997) 21201-21206.

[21] B. Thorens, A. Porret, L. Bühler, S.P. Deng, P. Morel, C. Widmann, Diabetes 42 (1993) 1678-1682.

[22] L.B. Knudsen, L. Pridal, Eur. J. Pharmacol. 318 (1996) 429-435.

[23] B.D. Green, M.H. Mooney, V.A. Gault, N. Irwin, C.J. Bailey, P. Harriott, B. Greer, P.R. Flatt, F.P. O'Harte, Metabolism 53 (2004) 252-259.

[24] J.J. Meier, A. Gethmann, M.A. Nauck, O. Götze, F. Schmitz, C.F. Deacon, B. Gallwitz, W.E. Schmidt, J.J. Holst, Am. J. Physiol. Endocrinol. Metab. 290 (2006) E1118-E1123.

[25] B.D. Green, N. Irwin, V.A. Gault, C.J. Bailey, F.P. O'Harte, P.R. Flatt, J. Endocrinol 185 (2005) 307-317.

[26] P.E. MacDonald, A.M. Salapatek, M.B. Wheeler, Diabetes 51 (2002) S443-S447.

27] C.M. Edwards, J.F. Todd, M. Mahmoudi, Z. Wang, R.M. Wang, M.A. Ghatei, S.R. Bloom, Diabetes 48 (1999) 86-93.

[28] D.P. Sonne, T. Engstrøm, M. Treiman, Regul. Pept. 146 (2008) 243-249.

[29] N.H. McClenaghan, P.R. Flatt, A.J. Ball, J. Endocrinol. 190 (2006) 889-986.

[30] S. Suga, T. Kanno, Y. Ogawa, T. Takeo, N. Kamimura, M. Wakui, Pflugers Arch. 440 (2000) 566-572.

[31] T.J. Kieffer, J.F. Habener, Endocr. Rev. 20 (1999) 876-913.

[32] J.R. Perez-Vallina, M.P. Revuelta, B. Cantabrana, A. Hidalgo, Life Sci. 61 (1997) 869-880.

[33] R. Omar, F.E. Bottrill, C.R. Hiley, R. White, Eur. J. Pharmacol. 401 (2000) 85-96

[34] B.P. Bullock, R.S. Heller, J.F. Habener, Endocrinology 137 (1996) 2968-2978.

[35] Y. Wei, S. Mojsov, FEBS Lett. 358 (1995) 219-224.

[36] Y. Wei, S. Mojsov, Acta Physiol. Scand. 157 (1996) 355-357.

[37] R.S. Clements Jr., D.S. Bell, Am. J. Med. 79 (1985) 2-7.

38] L.B. Knudsen, D. Kiel, M. Teng, C. Behrens, D. Bhumralkar, J.T. Kodra, J.J. Holst, C.B. Jeppesen, M.D. Johnson, J.C. de Jong, A.S. Jorgensen, T. Kercher, J. Kostrowicki, P. Madsen, P.H. Olesen, J.S. Petersen, F. Poulsen, U.G. Sidelmann, J. Sturis, L. Truesdale, J. May, J. Lau, Proc. Natl. Acad. Sci. USA. 104 (2007) 937942. 